\title{
SURROUNDED BY SOUND: NOISE, RIGHTS AND ENVIRONMENTS
}

\author{
In press: Crime, Media, Culture
}

Ascensión García Ruiz Ph.D.,

Assistant Professor of Criminal Law and Criminology, Department of Criminal Law, Complutense University of Madrid, Madrid, Spain. E-mail: ascensiongarcia@ucm.es

\author{
Nigel South Ph.D., \\ Professor, Department of Sociology, University of Essex, Colchester, United Kingdom. \\ E-mail: soutn@essex.ac.uk ; Orcid 0000-0001-5742-7257
}

\begin{abstract}
Noise was probably the first environmental pollutant (apart from human waste) in the Ancient world. Yet today, by comparison with other environmental matters, noise and protection from its effects are often overlooked, except in specialist fields such as architecture or planning. One major reason for this may be that noise does not possess the same ability to spread that is characteristic of other forms of pollution. Noise is also an unusual form of environmental pollution in having a physical impact it is 'heard' and can be 'felt' - but is predominantly interpreted subjectively. The impact and consequences of anthropogenic noise for humans and biodiversity in general, are currently under-investigated in criminology and are under-addressed in both public and private international environmental law. Here we question why noise has not (so far) been explored within green criminology and only tentatively explored within cultural criminology. The objectives are to provide an overview of noise as a topic, connecting media, culture, anti- and pro-social behaviour, and to unearth interconnections between the matter of noise and its implications for the environment.
\end{abstract}

Keywords: Noise, Environmental Law, Green-Cultural Criminology, Aesthetic Criminology, Sensory Criminology

\section{Introduction}

The 'sounds of the city' have long been of interest to cultural commentators because they are products and echoes of changes in urban life, music and style. Sound is one marker of the 'boundaries between normative acceptability and/or legality' (Millie, 2017: 4), between conformity and conflict, yet despite this, sound and noise have not received much attention in criminology. ${ }^{\text {i }}$ As a broad category, 'noise' has received more attention in other areas of study and public discourse - most obviously in relation to the growth and multiplication of forms of media, on the agendas of citizen associations, in the deliberations and debates of national and local politicians, and in the professions and practice of architects, urban planners and lawyers. Building upon the development of a 'green cultural criminology' (Brisman and South, 2013, 2014), this essay explores the scope for a criminology of sound, 
noise and the aural. In doing so, it aims to make a contribution to an emerging sensory criminology (visual (Brown and Carrabine, 2017; Natali and McClanahan, 2017), olfactory (Henshaw, 2014; Hsu, 2016), auditory (Atkinson, 2007; Hayward, 2012)), as well as the study of deviant leisure (Smith and Raymen, 2016), and of aesthetic uses and meanings of urban life and culture (Millie, 2017).

Noise is "taken for granted". In the "so-called visual regime of Western culture: in the West's hierarchy of the senses, the eye dominates the ear. This makes sound into a neglected issue' (Bijsterveld 2008: 2). Noise is often assumed to be a simple matter to produce or control ('turn up, turn down, turn off') yet is actually complex in terms of production and reception, national and international norms and responses, as well as its environmental implications. In addition, we should recognise that our 'hearing', interpretation and tolerance of noise changes over time. Historically, 'Like other semiotic systems, urban sound functioned on different levels and not every hearer gleaned the same things. Particular sounds might have different associations for different people according to rank, gender or origin.' (Garrioch, 2003: 5). Across the contemporary human lifecycle, the type, quantity, intensity, time of listening, repetition of noise, that we are willing to bear, aiming to enjoy, want, desire, seek out, will probably change as well.

Today, most countries in the world share relatively similar standards in relation to environmental protection in general but the subject of noise has characteristics that have not facilitated international agreement about how to conceptualise or interpret noise pollution (Brown, 2012: 74). In fact, different countries have determined quite different responses based on their respective cultures, societies, lifestyles and rules. In relation to regulation and law, this is neatly summarised by Parker (2015: 29-30) in his discussion of the idea of 'acoustic justice': 'It is as if contemporary approaches to law suffer a kind of deafness.' 'Matters of acoustics' he argues, only rarely 'feature in legal scholarship' and when they do, they are

invariably framed narrowly and uncritically as problems of mere rule or doxa ... Laws are made about sound, but the way in which sound is conceived for such purposes is barely reflected on. And for all its considerable attentions to language, contemporary jurisprudence has been far less interested in either voice or orality .... It cares about architectural but not acoustic space. It worries about the image and film but never the soundtrack.

It is commonly assumed that noise is intrusive and accepted that excessive noise can be harmful (Noise Free America, 2010; European Environment Agency, 2014). Noise can therefore be used aggressively and punitively, and technologies have been adapted or developed to weaponize noise. Instances range from the almost farcical use of high decibel rock music played $24 / 7$ by the US military as part of their siege tactics to encourage General Manuel Noriega, wanted on drug trafficking charges, to leave the Vatican Embassy in Panama City where he had taken refuge (The Economist, 2008), to 2014 reports of Ukrainian troops responding to Russian broadcast propaganda by loudly playing Cher's 'Shoop Shoop Song' (Macdonald, 2014). One example of sonic social control has been the use of 'the Mosquito', a device generating a high-pitched-noise that only the sensitive ears of young people can detect, employed to disperse unwelcome groups of teenagers (The Economist, 2008). This 'aural assault' followed experiments which included loud playing of classical music on the Tyne and Wear Metro in northern 
England, an idea later taken up by London Underground and Australian agencies that adopted a strategy of playing music that suburban teens would find "so "uncool" that it would drive them away from trouble-spots' (ibid). More aggressive forms of acoustic weaponization have been seen in the tactical use of noise and sonic weapons (e.g. Long Range Acoustic Devices) by police forces in 'order maintenance' operations and urban confrontations such as those in Ferguson, MO and the controversial purchase of 'sound cannons' by American police departments in Chicago and Baltimore. There is a process here of both the amplification of 'force', as well as the amplification of 'forces of nature' for this purpose, as elements of our environment - water, light and sound - are weaponized to support police and military power ${ }^{\text {ii }}$.

Notoriously, music and noise have also been employed as elements of abusive interrogation techniques. As noise is a prime source of orientation to our surroundings, both removal of sound and / or overload of aural input are disorientating and discomforting. As Cusick (2008: 4) notes, investigative historians and journalists have established that these interrogation practices 'constitute a coherently theorized arsenal of techniques developed from psychological research conducted in Canada, the United States and the United Kingdom in the 1950s, with funding from each country's national security agencies', (McCoy, 2006; Conroy, 2000; Mayer, 2005; Otterman, 2007) ${ }^{\text {iii }}$.

The effects of noise on human health are numerous, well known and the subject of substantial literatures in the fields of public health, audiology, and local governance, so this is not our focus here (see, for example, Goines \& Hagler, 2007; Hammer et al, 2014; DEFRA, 2010). This article examines noise in terms of its role in our living environments and the extensive sensory and physical landscapes that we inhabit and argues that we should consider noise from an ecological point of view. This requires a new approach to noise and a new outlook, integrating the effects of noise not only on human life but also on other species - animals and plants - that develop in their own natural environments. In general, noise has only prompted debate when humans are affected by noise-induced long term physical or mental damage and noise is rarely seen as a factor in options for the improvement of general environmental protection or considered as a serious 'pollutant'. In fact, few people are aware of the wide-range of noise-related phenomena and their consequences for social life and spaces, for a large variety of species, and for biodiversity.

The relevant literature is wide-ranging and cross-disciplinary so we first present characteristics, definitions and some applicable theoretical concepts. We build on this to synthesize the main propositions of various key works and then discuss interactions between social subjects and their environment, rights regarding expression and protection, and the notion of sound and noise as a point of intersection between cultural impact, social justice and environmental harm.

\section{Background: definitions and meanings of noise}

Schafer, a pioneering musicologist of our 'sonic environment', suggests that 'noises are the sounds we have learned to ignore' and that 'new' sounds of modernity differ in quality and intensity from those of the past (Schafer, 1973: 29). Other authors, from many different disciplines, assert that 'noise is any unwanted / undesired sound', or 'a sound which is out of place' and these definitions have become established in most 
regulations that are directed at the control of noise and excessive sound (Gurney, 1999: 6; Bell, 1966: 9-10; see also Goines \& Hagler, 2007).

Two principal lines of approach can be summarized. In one view, 'noise' as intense sound is relatively new, coming with the clamour of industrialization, and humans have adapted and learned to live with it as part of the urban condition. Alternatively, humans do not want to live with the 'infernal sounds' of the factory, the underground city or the vertical metropolis (Pike, 2007: 39), and 'adaptation' is simply grudging acceptance of an anti-social irritant, particularly unwelcome if 'excessive' and constantly 'intrusive' (however defined). From this point of view, like other assaults and pollutants, noise should be controlled (Flint, 2013: 151).

Yet it is not absolutely clear that the experience of a high level of noise emissions in terms of intensity is only a product of modernity (Hendy, 2014). Alongside contamination of water by human and animal body waste, noise is the first environmental pollutant and disturbance that still persists from the Ancient world. As Brañes (2010: 38) notes, the development of environmental law can really be traced back to its role in communities as they codified what was acceptable and normative public behaviour and what was not. For example, in the Greek city of Sibaris during the sixth century B.C., the sleep of inhabitants was disturbed by the noise made by roosters, provoking a ban on keeping the birds, while several artisan trades had to be relocated outside the city for similar reasons (Herrera, 2008: 25; Sánchez, 2009: 20). The Romans also initiated injunctions, albeit limited, in order to mitigate and diminish the enormous variety of noises that could be found in the heart of cities (García Ruiz, 2017: 14-20). English (2016) reminds us that 'Historically, our ears, not eyes, revealed what lay beyond the light of the campfire. And importantly, our ears helped us recognise what lay behind us, out of sight. Sound has the profound ability to haunt shock and terrify. It has a primordial quality that reaches deep inside us.' Early humans could do little to dampen the sounds of nature (the calls of animals, the noise of heaven and earth, thunder, earthquakes etc.) and the Biblical tale of the Battle of Jericho suggests noise as a weapon of war is not a new notion. As English (2016; see also Martín Mateo, 2007: 527) points out:

the story goes that Joshua's Israelite army was able to break down the walls of Jericho using the sound of their trumpets. Though there is no historical basis to the tale, it recognises the physiological and the psychological implications of sound in warfare. ... Like today, sonic fatigue leads to a psychological debilitation. Perhaps the Israelite army was able to wear the enemy down through prolonged high-volume sound projection, inducing sleep deprivation and fatigue-induced panic. Moreover, the constant blasting of the horns would act as a constant reminder that at any point, the armies might attack. The audible threat becomes a device of terror in and of itself.

Raising the volume of noise speaks - or shouts - of power. Hayward (2012: 458, citing Sloterdijk, 1998) notes that, 'since the earliest human congregation, groups have demarcated and protected their territory by emitting sounds', while, as Méndez (2016: 25) puts it in relation to challenges to such territorialism, 'In this game between positions, relations and powers, noise plays its role as interference within the socioacoustic order'. Yet, not all sounds considered by some to be 'noise' will be 'heard' in the same way by others. One person may be very tolerant or liberal in their expectations 
regarding levels of sound, while another may desire very strict limitations on sound emissions. According to Bijsterveld (2008: 2):

Hearing has a highly subjective side to it: sounds that annoy some people are music to the ears of others. Since noise is widely defined as "unwanted sound," the subjectivity inherent in this definition complicates legal intervention when rival definitions of noise arise.

\section{The intrinsic features of noise as 'different'}

Sound is a form of energy, a physical reality, and therefore its space and time coordinates can be measured with rigorous accuracy (Réfrégier, 2004). It has magnitude, resonance, space, pitch, intensity, and makes its effect felt through the physiology of hearing, and the transmission of sound to the brain (Bell, 1966; Bechtel, 1997; Bijsterveld, 2008). For humans the perception of sound is quite selective and is processed simultaneously with visual information (Tomatis, 1997; Hendy, 2014). These are factors that separate it from other environmental influences. Noise does not linger or remain in the atmosphere because the nature of noise is such that it is finite - it 'runs out' at the precise moment the emission is finished (Piercy et al, 1986: 96). It has spatial limits, usually having an impact only within a relatively restricted radius (Piercy et al, 1986; Réfrégier, 2004). It does not possess the same ability to spread that characterizes other forms of pollution (Bechtel, 1997; Goines \& Hagler, 2007). This characteristic makes noise distinctive when it comes to considering control (Brown, 2012: 73; García Ruiz, 2017: 5).

Without underestimating certain objective components, noise is a strongly subjectively determined and interpreted phenomenon. As Hegarty (2007: 3) notes, 'Noise is not an objective fact', it is generally perceived as a negative version of sound, and this 'occurs in relation to perception - both direct (sensory) and according to presumptions made by an individual. These are going to vary according to historical, geographical and cultural location. [...] Noise is a negative reaction, and then, usually, a negative response to a sound or set of sounds'. Studies from the fields of neuroscience and psychology show that a great profusion of noise can produce 'deviant' or 'disturbed' behaviours in people who have been previously affected by lack of sleep or particular mental health problems (Glass and Singer, 1972; Goines \& Hagler, 2007) but also in those previously considered as 'normal' by psychiatric protocols/standards (see e.g., Sokol and Thompson (2011) concerning the strength and influence of 'whines' or 'cries'). Kavaler (1977: 21-33) describes several instructive episodes, including a tragic homicide committed in New York:

four children were playing in front of a building in the Bronx [...] Suddenly, a barrel revolver appeared in the second-story window and several shots were heard [...] [T] he murderer confessed that he was a night shift worker and needed to sleep during the day. The noise caused by those boys playing in the street did not allow him to do so and he lost self-control.

Noise does not, by itself, produce medium or long-term alterations to the biophysical environment but it has a close relationship with odour, light and landscape pollution which may (García Ruiz, 2017: 249). 
Noise is a feature of numerous harms and crimes in the city and in the countryside, contributing, or being intrinsic, to various forms of pollution and ecological devaluation. The regulation of noise therefore occurs in various contexts for varying reasons. For example, in rural areas, noise restrictions may be applied in the interests of tourism, sustainability and natural protection, to encourage human enjoyment of landscapes and to help maintain species diversity within ecological systems. In the urban environment, noise is both a cause and consequence of other elements of social life which require specific forms of management. For example, 'Environmental AntiSocial Behaviour' in the urban context includes 'noise nuisance' and is a major factor in public perceptions of an uneasy and disquieting living space and hence a driver of regulatory interventions (Mackenzie et al, 2010; Flint, 2013). More widely, city populations engage in huge and unconstrained consumption of food, drink and other goods that are sold in disposable containers made of plastic, paper, metal and other types of organic / inorganic materials. As a consequence, for reasons of public health, aesthetics, tourism and as a function of local government paid for by taxation, waste collection and street cleaning are required and provided in urban areas (albeit variably and unequally, see e.g. Guerrero et al, 2013; Hastings et al, 2009).

The proliferation of bad odours left behind after inadequate or poor street cleaning, or due to the accumulation of urban waste associated with leisure activities, is closely correlated with the most extreme focal points of noise, i.e. occurring in areas which have a high density of visitors or an established commercial network dedicated mainly to leisure and recreation (Henshaw, 2014: 188; Millie, 2017: 9). Agnew's (2013) argument in favour of making efforts to slow down the kind of 'ordinary acts that lead to ecocide' can be drawn upon here, as his recommended changes in behaviour could generate different patterns of utilization of services provided by public administrations. One direct consequence would mean a significant reduction in the production and profusion of noise caused by these sources of sound on the streets, or at least the possibility of a modification of the timetables of the services, due to the fact that such services would not be so necessary nor needed so frequently.

The nexus between noise and light pollution is also important here and evident in the complexity of urban life in all contexts - work, leisure and the use of various services facilitating tourism, entertainment and the coexistence of citizens, and in the artificial lighting of artificial landscapes, i.e. human settlements (Rol de Lama et al, 2011). Light pollution can be defined as the alteration of natural levels of night lighting caused by anthropogenic sources of light and is receiving increasing interest (Falchi et al, 2016). The world atlas of artificial sky luminance shows that more than $80 \%$ of the world and more than $99 \%$ of the U.S. and European population live under light-polluted skies (Falchi et al, 2016). This has a consequent potential impact on culture that, historically, is of unprecedented magnitude. Moreover, light pollution has global ecological consequences contributing to loss of biodiversity, erosion of a key element of healthy life-balance ${ }^{\text {iv }}$, and waste of energy and money.

Effects of anthropogenic noise on animal and plant species 
Scientific evidence shows that high levels of noise emission have deleterious effects on flora and fauna, and thus on biodiversity (European Environment Agency, 2014; Francis and Barber, 2013; Radford et al, 2014; Gill et al, 2015). However, these impacts and their consequences are currently underappreciated and under-addressed in both public and private international environmental law (Parker, 2015; García Ruiz, 2017: 205). While it might be hoped that law and policy could be developed in a way that includes focus on the 'non-human', given the anthropocentric orientation of law and policy, it might instead be worth trying to conceptually unify the distinctive effects of noise on human as well as non-human species and establish actions that might be taken in response.

It is indisputable that anthropogenic noise harms ecosystems (Rabin et al, 2003) but the standards that might be used to assess the level of decibels causing damage are not adequately defined. This is partly because the standardized logarithmic system for measuring the scale of decibels does not consider infrasound and ultrasound which, respectively, have a frequency of vibrations lower or higher than the limits of perception of the human ear (Sáenz, 1986: 64; Hildebrand, 2009: 6). However, we do know that high levels of noise distort the visualization and perception of any landscape. As such noise also alters the biotic / biological conditions that any species native to the area will be dependent on for subsistence and development, resulting in the loss of biodiversity and the fragmentation of habitats (Francis et al, 2009; Barber et al, 2010). For instance, the way in which serins (small birds of the finch family) respond to anthropogenic noise has attracted wide research attention as it illustrates why noise is a determinant of biodiversity loss and arguments for preservation. Researchers suggest that birds are one of the best indicators of the real 'health' of our ecosystems (Koskimies, 1989; Gregory and Strien, 2010; Díaz et al, 2011) and ornithological studies have noted the decrease of some bird species caused by the proliferation of non-native birds in certain spaces, which may be the result of changes in migration related to changes to ambient conditions and climate, as well as legal and illegal importation of bird species (Møller et al, 2015; Díaz et al, 2015). The phenomenon of bee colony collapse has also been investigated in terms of the effects of 'atmospheric pollution', including the impact of noise and other vibrations and heavy metals as pollutants (Favre, 2011; Celli and Maccagnani, 2003; see Rucker et al (2016) on the economic consequences of the decline of bee populations).

'Noise' also affects aquatic life, e.g. whales become stranded on beaches as a result of exhaustion after attempting to evade anthropogenic sources of noise (Klein, 2017; Radford et al, 2014; Hildebrand, 2009). Currently there are no agreed international regulations about maritime traffic noise and the various activities that take place in the oceans. This is despite scientific evidence collected via numerous biological studies about the impacts of noise on aquatic environments where sound can travel hundreds and even thousands of kilometres (Barnes and Hughes, 2004; Weilgart, 2008; Moore et al, 2012). By contrast, the sense of sight only reaches several tens of meters.

While there have been some studies into the impact of aquatic and sub-aquatic noise on various marine species (Radford et al, 2014), those carried out on oceanic ecosystems remain surprisingly limited given how important the oceans are for the sustainability of the planet. Oceans are, of course, naturally noisy environments (waves, rain, lightning over water), but the argument that therefore marine wildlife are evolutionarily adapted 
to noise is not correct. This is because their adaptations only occur in response to natural sources of noise, which excludes those of an artificial nature (Radford et al, 2014). This topic is challenging considering its relevance to human use of the oceans. Maritime traffic helps to sustain trade flows, tourism and leisure activities and the interests of commerce and economic growth would support its expansion. However, such activities are dependent upon technologies that produce massive noise pollution that humans are largely unaware of, resulting from anthropogenic noise sources such as seismic exploration, sonar, acoustic deterrent and harassment devices, and so forth (Hildebrand, 2009; Eijgelaar et al, 2010; Radford et al, 2014: 1022).

\section{NOISE AND RIGHTS ‘TO’AND ‘IN’ THE CITY}

The greatest distinction between noise and other material forms of pollution is that although noise can be transmitted electronically over distance, it is based on local production and has immediate limits to its propagation (Piercy et al, 1986: 96). Noise and protection from its impacts, have not usually been considered a major issue for environmental concern although techniques such as 'sound level controls, noise mapping and noise abatement' are employed to help 'fight noise pollution or a bad soundscape' (Ciullo 2016) and, for example, to encourage better design of, or discourage flight paths over, urban environments. Ciullo describes a project (SONORUS, 2013) carried out in Brighton, UK, designed to investigate 'Soundscape and behavioural effects of introduced music in the acoustic environment'. Methodologically, the project was a simple demonstration of behaviour change based on observation of responses to different sound conditions but importantly, the study started from assuming that the acoustic background - or soundscape - is absolutely integral to the city not a secondary characteristic. It examined the quality of the soundscape as changed by a 'project of transformation' in the Valley Gardens in Brighton - an area that 'presented high noise levels', negatively affecting experience of 'the green areas present in the site.' The aim was to assist with 'planning of the acoustic environment' in ways that support 'wellbeing and health' for those living in cities.

The city is clearly the space where noise gains special importance for human society, although because there are 'cities within the city' (Young, 2014: 48), 'different people using the same space' will have 'different or overlapping ways of understanding city living' (Millie, 2017: 5). In what Atkinson (2007: 1906) calls the unseen city, the hope that peace and quiet may be practical in an urban environment comes up against the dynamic and elastic nature of city life, and the lack of precision in some regulations, and over-regulation in other cases. There is a tension or 'social strain' (Merton, 1938) here reflecting the fact that the social ecology (Atkinson, 2007) and utilisation of public space lie at a significant intersection of two culturally, economically and symbolically important sets of citizen rights, that is, rights to the city and rights in the city. In turn, this tension also affects rights with regard to public and private space.

By this we mean that a right to the city can be defined as the citizen's right to access everything that the city offers and to do so as an expression of human co-existence (Harvey, 2008; see also Lefebvre, 1968). The contrasting concept would be the matter of rights in the city - which would include various forms of protection regarding public use of city areas and districts, including a right to the peaceful and regulated use and enjoyment of city life and facilities. The rights derived from this latter conception of 
city usage would be the right to privacy (including domestic privacy), to silence and rest, and the right to expect regulations will be enforced and respected (García Ruiz, 2014: 377; 2017: 250-255).

Achieving and maintaining a balance between quiet and noise can strain popular desires and civil rights in the urban core of the city. As Atkinson (2014) suggests, for some "The desire to escape to the suburbs was arguably as much a wish to evade "The nerve wracking sleep-destroying noises of the city" (Fogelson, 2005: 119) as it was to achieve newfound space standards and amenities.' Ideally, the ecological system of urban life is able to generate equilibrium and establish behaviour patterns among citizens that enable them to freely exercise and enjoy their 'acoustic rights'. Of course, such harmony is not spontaneously or easily produced. The inevitable pursuit of 'noise' by certain social groups, such as young people (and not so young people), or the catharsis produced by this, are facilitators of socialization in the city. They are the sound of a city being alive. But the city and its citizens also need protection from disturbance and excess - carnival is only carnival if it is an exceptional celebration and has its limits. Balancing reasonable expectations and behaviour is difficult to achieve and as a result noise is ambivalently treated in the drafting and interpretation of 'city law' and 'law within the city', as relevant to a 'right to the city' and 'rights in the city' respectively (Harvey, 2008; Sassen, 1991; Young, 2014).

The following examples (far from exhaustive) represent a sample of the multiplicity of situations that might generate disturbing noise in cities (Petersen et al, 2017), which in some cases can also be harmful:

- The high-volume noise from the neighbour's party preventing / disturbing sleep, causing anxiety and possibly leading to disputes (Stokoe and Hepburn, 2005: 671 ), or lower-volume noise that may violate personal space in an embarrassing way, e.g. the unwanted and 'unasked-for intimacy' of what Gurney (2000:39) refers to as 'coital noise'.

- Excessive drinking at weekends (also contributing to litter and the visual degradation of the landscape).

- The sonic repercussions of tourism. Paradoxically while some parts of the city are sonically over-saturated, bringing the rights of residents and visitors into conflict, the characteristic sounds and other acoustic phenomena of particular places are a lure, contributing to 'sound tourism' (see Cox, 2014, and 'A travel Guide to Sonic Wonders': http://www.sonicwonders.org/).

- Air and road traffic - overhead, in front, behind, all around.

- High density concentrations of pubs, terraces, night clubs in particular areas.

- The use of public space for institutionalised festivities, sports, celebrations, street festivals and so on - a source of enjoyment for some but not others who feel disturbed and may feel excluded, resentful, left-out. Feeling alienated and isolated in the city is the classic irony of life among a multitude of others (Bijsterveld, 2008: 3-4; Gehl and Svarre, 2013).

The economic sector of city life obviously depends upon and encourages consumption which has its own music sound-track - muzak - playing in malls, shops, elevators, stations and so on (Macleod, 1979). Marketing has recognized that neurons and emotions can be harmonised. They are connected by perception, for example, through our sense of vision and the ways in which we interpret what we 'see' subjectively 
(Koelsch, 2010). They are also influenced by the sounds or noise of the contexts that we find ourselves in at each place and moment. Neuro-marketing techniques now reflect sophisticated knowledge about the function of both 'noise' and 'sound' (muzak, music) and 'silence' as sources of motivation and encouragement in consumer behaviour. An interesting recognition of this was the initiative introduced by Selfridges store in London in early 2013, to create silent spaces in the retail environment and 'invite' the shopper to 'celebrate the power of quiet, see the beauty in function and find calm among the crowds.' This was not a new idea but followed an innovation dating to the opening of the store in 1909 and the creation of a Silence Room where busy shoppers could find respite and calm, if only as a refreshing prelude to further engagement in the noise and heat of consumption. This is only one expression of how 'acoustic territories' (Labelle, 2010) have expanded to exert a particular form of social and behavioural 'control' in a manner that is not dependent upon the visible from which we usually receive such cues. As Hayward (2012: 458) puts it 'If Muzak was an early 'auditory marker' used to brand space and lubricate consumption, today, more sophisticated sonic ecologies function to demarcate territory for shopping / lifestyle promotion.'

Recognizing that the time and space geographies of diverse social groups are differentially affected by these auditory conditions and contexts, Atkinson (2007: 1907) has suggested the idea of a 'sonic ecology' as a spur to remapping our urban spaces. Noise is often 'underheard' in the sense that it may be peripherally noticeable but only as part of the blended background in any context, urban or rural. As part of the urban experience, noise is often celebrated yet is also at the top of lists of citizen complaints for those who live in cities ${ }^{\mathrm{v}}$. As Atkinson (2014) remarks, 'Noise is commonly held to be responsible for many psycho-social tensions, civil disputes and the ambient unease of much urban life.' Given that it is estimated that in three or four decades three quarters of the global population will be living in cities (World Urbanization Prospects, 2014), noise will inevitably be an issue to address in terms of quality of life, social harmony and regulation, and wider environmental impacts.

\section{Discussion: Citizen Noise, City Spaces and Competing Rights}

Noise can be a product of non-human 'nature', of human expression and activity, or of unnatural and technological mechanisms and systems - but it is also a cultural matter in the way it is created, received and interpreted. It has cultural meanings and cultural effects. Noise can be employed in various ways to support urban interventions that make a cultural and political point (Millie, 2017; Brisman and South, 2014) Noise is versatile in the sense that we can use one noise to overlay another, so we can listen to a noise of our choosing - though this may lead to discomfort for us and for others as the level of noise increases - an irony of 'amplification'. We also choose certain noise experiences over others - some say they cannot live without the sounds of the city and that the quiet of rural spaces would drive them mad. Others the opposite - Atkinson (2014) notes the 'effect of creating a built environment that pressures social subjects ... if we can hear them, they can hear us!' We may choose and enjoy certain spaces because of the noise and sounds we associate with them. People favour particular songs and music that they play electronically and 'in their head' as the soundtracks to their lives. These associations are the aural component of our everyday mental interpretations of what is 'going on' and also feature in the physical rhythms of our negotiation of the surfaces and contours of city spaces. 
To return to the distinction between rights to the city and rights in the city - the former is an expression of freedom to enjoy carnival and celebration, movement and pace, space and sound (Presdee, 2001). The latter is about desire for a life in the city on one's own terms, not those of the multitude, at least with regard to sensory experience. The ability to choose 'peace and quiet', as opposed to being involved in the noise, brutalism and violence of street encounters. This is what Atkinson (2015) describes as the 'desire to disconnect' as he refers to the 'strategies' that urban citizens use to 'find quieter pathways, searching out oases of reduced sound and the widespread application of noise-reducing technologies', all of which 'suggest a deep-seated need' for possible 'mental and psychic escapes' which we might imagine as 'islands' of calm and peace. This need, says Atkinson, signals a desire for 'new kinds of islandness even while inhabiting the maximal points of population concentration that we find in cities.' This is the search for escape from 'soundscapes where these impose a burden, distraction or even psychologically compressing and damaging experience.'

If desire for control over noise levels can be seen as a desire for 'peace', then the opposite - rejection of noise controls and exultation in loudness - might be seen as a manifestation of anti-social thoughtlessness, of aggression and power. Atkinson (2014) observes that, while 'noise is people just doing what they do', they may not realise that 'their personal freedoms may generate inwardly hating, stressed and sleepless lives in those around them'. At the same time, as already described, noise has always been part of the human arsenal of means of expressing superiority and power, trumpeting, raging or celebrating about ownership of territory and space.

Noise is an expression of physical energy and human activity, and involves both production and consumption, e.g. creating / performing, listening/ dancing. All this involves genuine enjoyment and diverse sensory experiences. However, there may also be limitations and constraints related to performance and consumption which act to displace potential for critique and resistance (Hall et al, 2008: 84-85).

\section{Noise: Retreat, Resistance, Critique}

Atkinson (2015) argues that 'All of us need a place to retreat to, whether it be the home or another home-like space that offers the possibility of peace, escape and a sense of control in our lives.' The impact of sound all-around, an environment of 360-degree exposure, is ultimately stressful and disorientating. For all its joys, cosmopolitanism, opportunities and diversity, the city is also exhausting and enervating and Atkinson (2015) points out that despite the development of technologies designed to reduce or mask noise, 'what Erving Goffman called the final 'territory of the self' ' remains 'easily assailed by sonic intrusions of various kinds.'

One model for the development of a living environment that offers a more peaceful, less conflictual way of life, closer to nature, is the idea of the 'eco-city'. This concept, as described by Lynch (2013: 49), draws on the work of Richard Register (1987, 2006) and his aim to offer an alternative vision of urban life drawing on 'ecologically sound urban management principles' to improve 'human lifestyles by decreasing the production of pollution and exposure to environmental toxins.' While Lynch refers to various elements of the interaction between 'the environment' and human life there is 
no reference to noise or sound. Yet in the same way that architecture, design and materials can contribute to ambitions to create more environmentally-responsible zerocarbon communities, techniques of 'building in' better sound insulation could enhance freedoms to enjoy sound and quiet (Atkinson, 2014; Roseland, 1997: 197-202). In the past, insulation was not necessarily a high priority for a building; today it is essential for reasons of energy efficiency but also to avoid the invasive cultural and technical productions of others. Living with noise is not a requirement, inevitability or necessary lifestyle choice for living in the city, as recognized for example by the development of an 'ambient noise strategy' for London (GLA, 2004: 74).

As with the distribution of all environmental 'goods and bads', 'the distribution of noise' is also a 'sociological matter that speaks to the issues of privacy, invasiveness and the zonal distribution of housing, buildings and services' (Atkinson, 2014). Profiteering and exploitation in the housing market, whether for sale or rent, has led to cutting standards, poor construction, use of cheap materials and a corresponding loss of quality of life, lack of sound insulation being just one manifestation of weak regulations and strong profit-orientations that have eroded privacy, autonomy and the scope for control over daily life (Atkinson, 2014).

Hayward (2012: 459) observes that although the 'soundscape' may seem 'ethereal', it requires 'criminological mapping' of cultural phenomena broadly speaking and noise pollution more specifically, to fully appreciate links between space and crime or social harms. The question that follows is "what kind of methodology might we employ for such an exercise?' In developing a green cultural criminology, one important development has been a visual criminology approach (see e.g. Natali and McClanahan, 2017) and it may be possible to develop an aural criminological method in parallel. We could also consider how environmentally sensitive crime-prevention ideas might be applied to noise pollution and the anti-social discomforts and harms associated with it. Various crime-prevention measures already reflect green principles (Brisman and South, 2015) and factor in the attraction, distraction and disruption caused by noise. For example, various spatial features intended to contribute to crime-prevention through environmental design employ green planting and landscaping approaches that are intended to create boundaries, markers, visual instructions and so on, but - importantly - also have a calming and noise-dampening effect (Cherulnik, 1993: 159-163; Pretty et al, 2013; García Ruiz, 2017: 74). The notion of 'calming' also plays a role in trying to reduce road traffic and pedestrian or cyclist injury and deaths, as well as the noise and air pollution caused by cars. The ultimate 'calming control' with regard to motorised vehicles is to enforce traffic-free areas, reducing pollutants, encouraging healthy mobility, and creating a calmer and quieter environment (Forman et al, 2003).

\section{CONCLUSION}

'Sound' is a primary source, means and site of cultural production yet is relatively neglected in criminology (Hayward, 2017: 146-7). Music (e.g. Hirsch, 2012, Spunt, 2014), and the noise of crowds, riots or protest, have received attention but so much of the auditory backdrop to daily life is taken for granted and its effects and influences invisible and filtered by our perceptions of what is 'important' - are barely noted or investigated. Yet sound is a cause and signal of, as well as a medium for recording and 
re-playing, important moments and points where cultural impact, social justice and environmental harm intersect and collide ${ }^{\mathrm{vi}}$.

Sounds and noises surround us: sometimes hardly heard yet omnipresent; at other times, dominant, unavoidable. This has always been so but not always in the same ways, as Garrioch (2003: 5) points out in relation to the noise of the city and the flawed assumptions of urban historians who 'have paid little attention to urban sound, tending to assume that even if the sounds themselves were different, the role they played was similar. ... yet just as people in the past interpreted the visual world differently, so too they experienced sound differently from the way we do.'

In developing a criminology concerned with the intersection between the environment, the senses and human sensibilities, both the historical and contemporary varieties and interpretations of sound and noise require further study. This would contribute to necessary thinking about what we want or need from cities as places where we might find spaces for peace, for example addressing acoustic victimization in terms of environmental justice.

The argument here calls for interdisciplinary explorations of the sonic environment we inhabit. It aims to contribute to the development of green-cultural criminology (Brisman and South, 2014), and complements the study of 'deviant leisure' (Smith and Raymen, 2016) and visual criminology (Brown and Carrabine, 2017). Brown (2017) and Millie (2017: 4) both detect a turn toward consideration of the sensory, the embodied, the affective, the emotional and the aesthetic. A future criminology of the senses and cultural sensibilities must build on the foundations provided by explorations of aural, visual, olfactory, aesthetic and related experiences of environmental (in)justice.

Acknowledgements: Many thanks to Rowland Atkinson and two anonymous reviewers for very helpful comments and suggestions.

The Authors declare that there is no conflict of interest.

This research received no specific grant from any funding agency in the public, commercial, or not-for-profit sectors.

\section{NOTES}

i Here we do not simply mean 'music' which has been extensively covered in criminology and cultural studies.

ii We are very grateful to an anonymous reviewer for emphasising these points.

iii Recent work shows how prisoners of the Iraq war were tortured through exposure to high level and intermittent noise at the Guantanamo Bay detention camp (Hirsch, 2012). See also a recent Judgment of the European Court of Human Rights, Case of Husayn (Abu Zubaydah) v. Poland of 16 February 2015 [Final version], in relation to the use of techniques such as white noise or loud music within the so-called 'High-Value Detainees Programme' designated for suspected terrorists by the US Government. Available at: www.hudoc.echr.coe.int. 
iv In modern cities, the natural cycle of transition from 'light to dark to light' has been distorted. One consequence of an excess of artificial light at night is disturbance of circadian rhythms which influence the chemical synthesis of melatonin in the body and hence sleep/wake cycles (Rol de Lama et al, 2011: 20-22).

$\checkmark$ For example, inter alia, the following are merely representative of numerous antinoise organisations: Ligue Française contre le Bruit (France); Nederlandse Stichting Geluidshinder (Netherlands); British Noise Abatement Society (United Kingdom); Deutscher Arbeitsring für Lärmbekämpfung (Germany); League for the Hard of Hearing (United States); Plataforma Estatal de Asociaciones Contra el Ruido y las Actividades Molestas (Spain); International Consortium on Noise Issues in Emerging and Developing Countries. See more in: (González: 2012, 145-163; Bijsterveld: 2008, 7-8).

${ }^{\mathrm{vi}}$ For a similar argument in relation to visual representation of environmental harms in cinema, see McClanahan et al (2017).

\section{REFERENCES}

Agnew R (2013) The ordinary acts that contribute to ecocide. A criminological analysis. In: South, $\mathrm{N}$ and Brisman A (eds.) Routledge International Handbook of Green Criminology. New York: Routledge, pp. 58-72.

Atkinson R (2007) Ecology of sound: The sonic order of urban space. Urban Studies 44 (10): 1905-1917.

Atkinson R (2014) The sonic ghetto. In: Crime Capital: urban life in superpolarised cities. Available at: https://autotomically.wordpress.com/2014/10/25/thesonic-ghetto/ (accessed 21 November 2017).

Atkinson R (2015) The sonic island: Urban noise and the value of isolation. In Crime Capital: urban life in super-polarised cities. Available at: https://autotomically.wordpress.com/category/anti-social-behaviour/ (accessed 31 July 2017).

Barber J, Crooks K and Fristrup K (2010) The costs of chronic noise exposure for terrestrial organisms. Trends Ecol Evol 25(3): 180-189.

Barnes R and Hughes R (2004) An Introduction to Marine Ecology (3 ${ }^{\text {th }}$ ed.) Oxford: Wiley-Blackwell.

Bechtel RB (1997) Environment and Behavior. An Introduction. California: Sage Publications.

Bell A (1966) Noise. An Occupational Hazard and Public Nuisance. Public Health Papers, 30. Geneva: World Health Organization.

Bijsterveld K (2008) Mechanical Sound: Technology, Culture, and Public Problems of Noise in the Twentieth Century. Cambridge: MIT Press.

Brañes R (2010) Manual de Derecho Ambiental Mexicano. México D.F.: Fondo de Cultura Económica.

Brisman A and South N (2013) 'For a green-cultural criminology', Crime, Media, Culture, 9, 2, 115-135.

Brisman A and South N (2014) Green Cultural Criminology: Constructions of Environmental Harm, Consumerism, and Resistance to Ecocide. London: Routledge.

Brisman A and South N (2015) An assessment of Tonry and Farrington's four major crime prevention strategies as applied to environmental crime and harm. Journal of Criminal Justice and Security (Varstvoslovje) 17(2): 127-151. 
Brown AL (2012) A review of progress in soundscapes and an approach to soundscape planning. International Journal of Acoustics and Vibration 17(2): 73-81.

Brown, M (2017) Visual criminology. Oxford Research Encyclopedia of Criminology. DOI: 10.1093/acrefore/9780190264079.013.206

Brown M and Carrabine E (eds) (2017) The Routledge Handbook of Visual Criminology. Abingdon: Routledge.

Celli G and Maccagnani B (2003) Honey bees as bioindicators of environmental pollution. Bulletin of Insectology 56(1): 137-139.

Cherulnik P (1993) Applications of environment-behavior research. Case studies and analysis. Cambridge: Cambridge University Press.

Ciullo P (2016) Soundscape and behavioural effects of introduced music in the Acoustic environment: a field experiment. Politecnico di Torino, Architettura Costruzione Città. Available at: http://webthesis.biblio.polito.it/4634/ (accessed 21 November 2017).

Cox T (2014) Sonic Wonderland. A Scientific Odyssey of Sound. London: Bodley Head.

DEFRA (2010) Noise Policy Statement for England. London: Department for Environment, Food and Rural Affairs.

Díaz M, Cuervo J, Grim T et al (2015) Interactive effects of fearfulness and geographical location on bird population trends. Behavioral Ecology 26(3): 716-721.

Díaz M, Parra, A and Gallardo C (2011) Serins repond to anthropogenic noise by increasing vocal activity. Behavioral Ecology 22(2): 332-336.

Economist, The (2008) 'Turn that noise off': The use and misuse of sound', The Economist, February 16th. http://www.economist.com/node/10711614 (accessed 21 November 2017).

Eijgelaar E, Thaper C and Peeters, P (2010) Antarctic cruise tourism: the paradoxes of ambassadorship, "last chance tourism" and greenhouse gas emissions. Journal of Sustainable Tourism 18(3): 337-354.

English L (2016) The sound of fear. The Conversation, 6 October. Available at: https://theconversation.com/friday-essay-the-sound-of-fear-65230.

European Environment Agency (2014) Living well, within the limits of our planet. Available at: http://ec.europa.eu/environment/pubs/pdf/factsheets/7eap/en.pdf (accessed 21 November 2017).

Falchi F, Cinzano P, Dan D, Kyba C, Elvidge CD and Baugh K (2016) The new world atlas of artificial night sky brightness. Science Advances 2(6) 3 June. DOI: 201610.1126/sciadv.1600377.

Favre D (2011) Mobile phone-induced honeybee worker piping. Apidologie 42(3): 270-279.

Flint J (2013) Reconfiguring urban Britain: policing, spatial justice and postmodern (in)security. In: Lippert R and Walby K (eds) Policing Cities. Abingdon: Routledge, pp. 147- 160.

Fogelson R (2005) Bourgeois Nightmares: Suburbia, 1870-1930. New Haven: Yale University Press.

Forman RT, Sperling, D, Bissonette JA et al (2003) Road Ecology. Science and Solutions. Washington: Island Press.

Francis C and Barber JR (2013) A framework for understanding noise impacts on wildlife. Frontiers in Ecology and the Environment, 11(6): 305-313.

Francis C, Ortega C and Cruz A (2009) Noise pollution changes avian communities and species interactions. Current Biology 19: 1415-1419, August 25.García Ruiz A (2014) Modernos paradigmas ambientais: o neoconstitucionalismo 
latinoamericano de corte biocêntrico e seu vínculo com a denominada green criminology (ou sua influência no direito penal atual). Revista Forense 419(110): 367380 .

García Ruiz A (2017) Green Criminology. El ruido: un intruso en el Derecho penal medioambiental. Montevideo - Buenos Aires: BdeF.

Garrioch, D (2003) Sounds of the city: the soundscape of early modern European towns. Urban History, 30 (1): 5-21.

Gehl J and Svarre B (2013) How to study public life. Washington: Island Press.

Gill S, Job J, Myers K et al (2015) Toward a broader characterization of anthropogenic noise and its effects. Behavioral Ecology 26(2): 328-333.

GLA (2004) Sounder City:The Mayor's Ambient Noise Strategy, London: Greater London Authority.

Glass DC and Singer JE (1972) Urban Stress: Experiments on Noise and Social Stressors. New York: Academia Press.

Goines L and Hagler L (2007) Noise Pollution: A Modern Plague. Southern Medical Journal 100(3): 287-294.

González AE (2012) Contaminación Sonora y Derechos Humanos. Serie Investigaciones: Derechos Humanos en las Políticas Públicas (2). Uruguay: Defensoría del Vecino de Montevideo.

Gregory R and Strien A (2010) Wild bird indicators: using composite population trends of birds as measures of environmental health. Ornithological Science 9: 3-22.

Gurney C (2000) Transgressing private-public boundaries in the home: a sociological analysis of the coital noise taboo. Venerology 13(1): 39-46.

Guerrero L, Maas G and Hogland W (2013) Solid waste management challenges for cities in developing countries. Waste Management 33(1): 220-232.

Gurney C (1999) Rattle and hum: gendered accounts of noise as a pollutant: an aural sociology of work and home. Health and Safety Authority Conference. York.

Hall S, Winlow S and Ancrum C (2008) Criminal Identities and Consumer Culture. Cullompton: Devon.

Hammer M, Swinburn T and Neitzel R (2014) Environmental Noise Pollution in the United States: Developing an Effective Public Health Response. Environmental Health Perspectives 122(2):115-119.

Harvey D (2008) The right to the city. New Left Review 53:23-40.

Hastings, A, Bailey, N, Bramley, G, Croudace, R and Watkins, D (2009) Street Cleanliness in Deprived and Better -off Neighbourhoods: A Clean Sweep, York: Joseph Rowntree Foundation. Available at: https://www.jrf.org.uk/report/street-cleanlinessdeprived-and-better-neighbourhoods-clean-sweep (accessed 21 November 2017).

Hayward KJ (2012) Five spaces of cultural criminology. British Journal of Criminology 52(3): 441-462.

Hayward, K (2017) Documentary criminology. In: Brown, M and Carrabine, E (eds) The Routledge Handbook of Visual Criminology. Abingdon: Routledge.

Hegarty P (2007) Noise / Music: A History. New York-London: Bloomsbury. Books.

Hendy D (2014) Noise. A Human History of Sound \& Listening. London: Profile

Herrera del Rey JJ (2008) La defensa jurídica contra la contaminación acústica. Madrid: La Ley.

Henshaw S (2014) Urban Smellscapes: Understanding and Designing City Smell Environments. Abingdon: Routledge.

Hildebrand JA (2009) Anthropocentric and natural sources of ambient noise in the ocean. Mar Ecol Prog Ser 395: 5-20. 
Hirsch L (2012) Music in American Crime Prevention and Punishment. Michigan: University of Michigan Press.

Hsu H (2016) Naturalist smellscapes and environmental justice. American Literature 88(4): 787-814.

Kavaler L (1977) Ruido: La nueva amenaza. Buenos Aires: Tres Tiempos.

Klein J (2017) A search for clues to what causes whale strandings. New York Times, 16 March. Available at: https://www.nytimes.com/2017/03/16/science/whatcauses-whale-strandings.html (accessed 21 November 2017).

Koelsch S (2010) Towards a neural basis of music-evoked emotions. Trends in Cognitive Sciences 14(3):131-137.

Koskimies P (1989) Birds as a tool in environmental monitoring. Ann. Zool. Fennici 26: 153-166.

Labelle B (2010) Acoustic Territories, Sound Culture and Everyday Life. New York: Continuum.

Lefebvre H (1968) Le droit à la ville. Paris: Anthropos. Paris: Economica.

Lynch M (2013) Reflections on green criminology and its boundaries: Comparing environmental and criminal victimization and considering crime from an eco-city perspective. In: South N and Brisman A (eds.) Routledge International Handbook of Green Criminology. New York: Routledge, pp. 43-57.

MacDonald F (2014) Ear assault in Ukraine: Music as a weapon. BBC Culture, 21 October. Available at: http://www.bbc.com/culture/story/20140310-ear-assaultmusic-as-a-weapon (accessed 21 November 2017).

Mackenzie S, Bannister J, Flint J, Parr S, Millie A and Fleetwood J (2010) The Drivers of Perceptions of Anti-Social Behaviour, Research Report 34 March, London: Home Office.

Macleod B (1979) Facing the muzak. Popular Music \& Society 7(1):18-31.

Martín Mateo R (2007) El ruido una problemática social básicamente interdisciplinar. In: Moreno Martínez, J (coord.) La responsabilidad civil y su problemática actual. Madrid: Dykinson, 519-535.

McClanahan B, Brisman A and South N (2017) Green Criminology, Culture and Cinema. In: Brown M and Carrabine E (eds) Oxford Encyclopedia of Crime, Media, and Popular Culture. New York: Oxford University Press.

Méndez Rubio A (2016) Política del ruido. En los límites de la comunicación musical. Methados. Revista de ciencias sociales 3(1): 21-35.

Merton R (1938) Social structure and anomie. American Sociological Review 3: 672-682.

Millie A (2017) Urban interventionism as a challenge to aesthetic order: Towards an aesthetic criminology. Crime, Media, Culture 13(1): 3-20.

Møller A, Tryjanowski P, Díaz M et al (2015) Urban habitats and feeders both contribute to flight initiation distance reduction in birds. Behavioral Ecology 26(3): 861-865.

Moore S, Reeves R, and Southall B (2012) A new framework for assessing the effects of anthropogenic sound on marine mammals in a rapidly changing Arctic. BioScience 62(3):289-295.

Natali L and McClanahan B (2017) Perceiving and communicating environmental contamination and change: Towards a green-cultural criminology 'with' images. Critical Criminology 25(1): 199-214.

Parker J (2015) Acoustic Jurisprudence. Oxford: Oxford University Press. 
Petersen L, Jöhncke S and Skårup B (2017) Noise, Social Housing and Sleep: A Social Science Review. Copenhagen: University of Copenhagen, Faculty of Social Sciences.

Piercy JE, Embleton TFW and Sutherland LC (1986) Review of noise propagation in the atmosphere. In: Saenz A and Stephens R (eds.) Noise Pollution: Effects and Control. London: Wiley, 95-132.

Pike D (2007) Metropolis on the Styx: The Underworlds of Modern Urban Culture, 1800-2001. Ithaca: Cornell University Press.

Presdee M (2001) Cultural Criminology and the Carnival of Crime. London: Routledge.

Pretty J, Wood C, Bragg R and Barton J (2013) Nature for rehabilitating offenders and facilitating therapeutic outcomes for youth at risk. In: South $\mathrm{N}$ and Brisman A (eds) Routledge International Handbook of Green Criminology. Abingdon: Routledge, 184-196.

Rabin L, McCowan B, Hooper S and Owings D (2003) Anthropogenic noise and its effect on animal communication: An interface between comparative psychology and conservation biology. International Journal of Comparative Psychology 16(2):172-192.

Radford A, Kerridge E and Simpson S (2014) Acoustic communication in a noisy world: can fish compete with anthropogenic noise? Behavioral Ecology 25(5): 1022-1030.

Réfrégier P (2004) Noise Theory and Application to Physics. From Fluctuations to Information. New York: Springer.

Rol de Lama M, Baño Otálora B, Martínez Nicolás A et al (2011) El lado oscuro de la luz: efectos de la contaminación lumínica sobre la salud humana. Física y Sociedad (Revista del Colegio Oficial de Físicos. Ejemplar dedicado a Contaminación Lumínica y eficiencia energética (21):20-22.

Roseland M (1997) Dimensions of the eco-city. Cities 14(4):197-202.

Rucker R, Thurman W and Burgett M (2016) Colony collapse and the economic consequences of bee disease: Adaptation to environmental change. Working Paper 16018, Raleigh, NC: Center for Environmental and Resource Economic Policy.

Sáenz A (1986) Physics of noise. In Sáenz A and Stephens R (eds) Noise Pollution: Effects and Control. London: Wiley, 45-94.

Sánchez Sahorí F (2009) Apuntes para una filosofía del ruido. In Pinedo Hay J (coord.) El ruido en las ciudades. Análisis jurídico-práctico. Barcelona: Bosch, 17-50.

Sassen S (1991) The Global City: New York, London, Tokyo. Princeton: Princeton University Press.

Schafer, RM (1973) The Music of the Environment. Vienna: Universal Edition.

Smith O and Rayment T (2016) Deviant leisure: A criminological perspective. Theoretical Criminology, August.

Sokol Chang R and Thompson NS (2011) Whines, cries and motherese: their relative power to distract. Journal of Social, Evolutionary, and Cultural Psychology 5(2): 10-20.

Sound Tourism. A Travel Guide to Sonic Wonders (2017). Available at: http://www.sonicwonders.org/ (accessed 21 November 2017).

South N (2014) Green criminology, environmental crime prevention and the gaps between law, legitimacy and justice. Journal of Criminal Investigation and Criminology (Revija za Kriminalistiko in Kriminologijo) 65(4): 373-381.

Spunt B (2014) Heroin and Music in New York City. New York: Palgrave.

Stokoe E and Hepburn A (2005) You can hear a lot through the walls: Noise formulations in neighbour complaints. Discourse and Society 16(5): 647-673. 
Tomatis A (1997) The Ear and Language. New York: Stoddart.

Weilgart LS (2008) The Impact of Ocean Noise Pollution on Marine

Biodiversity. International Ocean Noise Coalition. Available at:

https://awionline.org/content/international-ocean-noise-coalition (accessed 21

November 2017).

World Urbanization Prospects (2014) The 2014 Revision, Highlights

(ST/ESA/SER.A/352) United Nations, Department of Economic and Social Affairs, Population Division. Available at:

https://esa.un.org/unpd/wup/publications/files/wup2014-highlights.pdf (accessed 21 November 2017).

Young, A (2014) Street Art, Public City: Law, Crime and the Urban Imagination, Abingdon: Routledge. 